\title{
Stability-indicating HPLC-DAD/UV-ESI/MS impurity profiling of the anti-malarial drug lumefantrine
}

Mathieu Verbeken ${ }^{1 \dagger}$, Sultan Suleman ${ }^{1,3 \dagger}$, Bram Baert ${ }^{1}$, Elien Vangheluwe ${ }^{1}$, Sylvia Van Dorpe ${ }^{1}$, Christian Burvenich², Luc Duchateau², Frans H Jansen", Bart De Spiegeleer ${ }^{1 *}$

\begin{abstract}
Background: Lumefantrine (benflumetol) is a fluorene derivative belonging to the aryl amino alcohol class of antimalarial drugs and is commercially available in fixed combination products with $\beta$-artemether. Impurity characterization of such drugs, which are widely consumed in tropical countries for malaria control programmes, is of paramount importance. However, until now, no exhaustive impurity profile of lumefantrine has been established, encompassing process-related and degradation impurities in active pharmaceutical ingredients (APIs) and finished pharmaceutical products (FPPS).

Methods: Using HPLC-DAD/UV-ESI/ion trap/MS, a comprehensive impurity profile was established based upon analysis of market samples as well as stress, accelerated and long-term stability results. In-silico toxicological predictions for these lumefantrine related impurities were made using Toxtree ${ }^{\circledR}$ and Derek ${ }^{\circledR}$.

Results: Several new impurities are identified, of which the desbenzylketo derivative (DBK) is proposed as a new specified degradant. DBK and the remaining unspecified lumefantrine related impurities are predicted, using Toxtree $^{\circledR}$ and Derek ${ }^{\circledR}$, to have a toxicity risk comparable to the toxicity risk of the API lumefantrine itself.

Conclusions: From unstressed, stressed and accelerated stability samples of lumefantrine API and FPPS, nine compounds were detected and characterized to be lumefantrine related impurities. One new lumefantrine related compound, DBK, was identified and characterized as a specified degradation impurity of lumefantrine in real market samples (FPPs). The in-silico toxicological investigation (Toxtree ${ }^{\circledR}$ and Derek ${ }^{\circledR}$ ) indicated overall a toxicity risk for lumefantrine related impurities comparable to that of the API lumefantrine itself.
\end{abstract}

\section{Background}

Lumefantrine (benflumetol) is a 2,4,7,9-substituted fluorene (2,3-benzindene) derivative (Figure 1). It was synthesized in the 1970 s by the Academy of Military Medical Sciences, in Beijing, and registered in China for anti-malarial use in 1987. It is now commercially available in fixed combination products, mostly with $\beta$ artemether (ACT, artemisinin-based combination therapy), which are proven to be highly efficacious for treatment of uncomplicated falciparum malaria. In addition to the compound itself, the compound proved to possess marked blood schizontocidal activity against

\footnotetext{
* Correspondence: Bart.Despiegeleer@UGent.be

+ Contributed equally

'Drug Quality and Registration (DruQuaR) group, Faculty of Pharmaceutical Sciences, Ghent University, Harelbekestraat 72, B-9000 Ghent, Belgium Full list of author information is available at the end of the article
}

a wide range of Plasmodium, among them chloroquine-resistant Plasmodium falciparum [1-5].

Biochemical studies suggest that its anti-malarial effect involves lysosomal trapping of the drug in the food vacuole of the intra-erythrocytic parasite, followed by binding to haem that is produced in the course of haemoglobin digestion. This binding prevents the polymerization of haem into haemozoin, hence inhibiting the detoxification of haem. Investigations involving aryl-methanol compounds have suggested the coordination of the iron centre of haem (Fe(III)PPIX) and related porphyrins by the alcohol functionality, indicating the structural activity relationship of the antimalarial drug lumefantrine [6]. Hence, structural analogues of lumefantrine also posses marked antimalarial effects. Halofantrine, an aryl amino alcohol analogue of lumefantrine, is also an anti-malarial drug, but is known to be potentially cardiotoxic [7].

\section{(Ciomed Central}




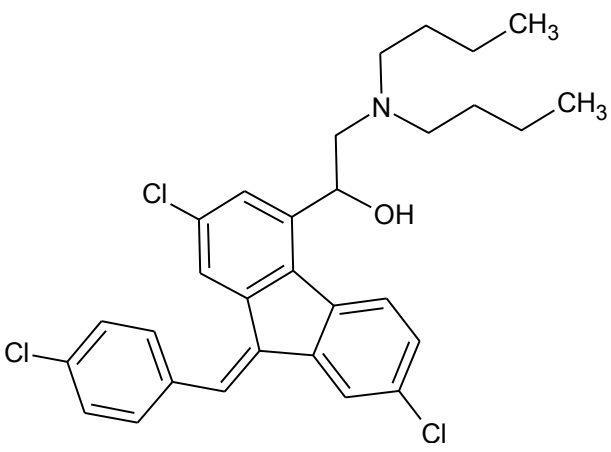

Figure 1 Structure of Lumefantrine.

Monodesbutyl-benflumetol, a metabolite of lumefantrine, exerts higher blood schizontocidal activity in Plasmodium falciparum, as well as in Plasmodium vivax. It is about 10-times more effective then lumefantrine [8]. The secondary alcohol permits the formation of dextrorotatory and levorotatory lumefantrine enantiomers and routine synthesis yield the racemate of (+)-lumefantrine and (-)-lumefantrine, which have almost identical potency. Therefore, from the activity point of view, there is no reason to use only one of the enantiomers of lumefantrine instead of the racemate. Moreover, in view of the low animal and human toxicity of the lumefantrine racemate, no major toxicological differences between the two enantiomers are expected [9]. However, other impurities resulting from synthesis might be present.

Lumefantrine containing combinations are incorporated in the WHO essential drug list for the treatment of malaria in endemic areas of the tropical climate. Due to the logistic system [10], degradation products may be spontaneously generated during distribution and storage. Control of such impurities in drug substances and finished drug products is required as they might impart different efficacy and bioavailability to the drug and/or they might produce different adverse and toxic effects to the patients [11].

The safety of a drug product is dependent not only on the toxicological properties of the active drug substance, but also on the toxicological properties of its impurities [12]. Thus, there is an ever-increasing interest in impurities present in APIs and FPPs [13]. Impurity profiling (i.e. the identity as well as the quantity of impurities in the pharmaceutical drug) is now gaining critical attention from regulatory authorities. The different Pharmacopoeias, such as the European Pharmacopoeia (Ph. Eur.), United States Pharmacopeia (USP) and International Pharmacopoeia (Ph.Int.) are incorporating specification limits to acceptable levels of impurities present in the API's or FPPs formulations, based upon found levels in approved market samples $[11,14,15]$. Moreover, ICH guideline Q3A(R) stipulates different thresholds or action limits based upon the maximum daily dose (MDD). For lumefantrine formulations (FPP), with a MDD of $960 \mathrm{mg} /$ day, these are defined as $0.10 \%$ reporting threshold, $0.20 \%$ identification threshold and $0.20 \%$ qualification threshold [16].

USP Salmous (Standards for Articles Legally Marketed Outside the US) and Ph. Int. have already established specification limits for three lumefantrine related impurities: lumefantrine related compound $\mathrm{A}$ ((RS,Z)-2-(Dibutylamino)-2-(2,7-dichloro-9-(4-chlorobenzylidene)-9H-fluoren-4-yl)ethanol), lumefantrine related compound $\mathrm{B}_{\mathrm{A}}((1 \mathrm{~S}, 3 \mathrm{R}, 5 \mathrm{R})-1,3-\mathrm{bis}((\mathrm{EZ})-2,7-$ Dichloro-9-(4-chlorobenzylidene)-9H-fluoren-4-yl)-2,6dioxabicyclo[3.1.0]hexane) and lumefantrine related compound $\mathrm{B}_{\mathrm{B}}$ ((2-((EZ)-2,6-Dichloro-9-(4-chlorobenzylidene)-9H-fluoren-4-yl)-3'-((EZ)-2,7-dichloro-9-(4chlorobenzylidene)-9H-fluoren-4-yl)-2,2'-bioxirane). The USP Salmous specification limits of these impurities are $0.1 \%$ for both impurities $A$ and $B_{A}$ and $0.3 \%$ for impurity $B_{B}$ [17]. The Ph.Int. lumefantrine monograph lists the same three compounds as identified potential impurities, with specification limits of $0.1 \%$ for impurity $A$ and $0.3 \%$ for impurity $B_{A}$ and $B_{B}$ [18].

Analytical procedures have been reported for the assay of lumefantrine in different FPPs, using HPLC-UV [19-22]. Furthermore, an LC/MS/MS bio-analytical method for quantification of lumefantrine in human plasma has been developed [23]. However, no impurity profile has been established for this drug, while this is considered much more critical than the assay value. In this study, the potential impurities are described, including new degradants, as well as their relevance towards specification settings and in-silico toxicological evaluation. APIs and FPPs containing lumefantrine were evaluated by HPLC, with UV detection for quantification and with ESI-iontrap MS detection for identification.

\section{Methods}

\section{Samples and chemicals}

All drug substance batches (APIs), commercially available FPPs (Co-Artesiane ${ }^{\circledR}$, Artefan ${ }^{\circledR}$, Lumartem ${ }^{\circledR}$ and Coartem $^{\circledR}$ ) and the standard of desbenzylketo (DBK) lumefantrine derivative were supplied by Dafra Pharma International (Belgium). USP-Salmous standards of lumefantrine and impurity A were purchased from U.S. Pharmacopeia (Basel, Switzerland). Analytical solutions were prepared in HPLC grade tetrahydrofuran (Fisher Scientific, Leicestershire, UK) at a concentration of 0.96 $\mathrm{mg} / \mathrm{ml}$ lumefantrine, which corresponds to $100 \%$ label claim (l.c.). A dilution equivalent to $0.5 \%$ l.c. is also prepared and used for the quantification of the related impurities. Hydrogen peroxide $\left(\mathrm{H}_{2} \mathrm{O}_{2}\right)$, sodium hydroxide $(\mathrm{NaOH})$ and ammonium acetate were purchased 
from Merck (Darmstadt, Germany), hydrochloric acid $(\mathrm{HCl})$ from Sigma-Aldrich (St Louis, USA) and glacial acetic acid from Riedel-de Haën (Seelze, Germany). Sartorius (Göttingen, Germany) ultrapure 18.2 M $\Omega . c m$ quality water and HPLC grade acetonitril (Romil, Cambridge, UK) were used for HPLC-UV/MS analysis.

\section{Liquid chromatography}

HPLC-UV investigation of the impurity profiles was performed on a HPLC-PDA apparatus consisting of a Waters Alliance 2695 separation module and a Waters 2998 photodiode array detector with Empower 2 software for data acquisition (all Waters, Milford, MA, USA). For PDA detection, the UV spectrum was recorded at 190-400 $\mathrm{nm}$. Quantification was performed at $266 \mathrm{~nm}$. The positive ion ESI and the collisioninduced dissociation (CID) mass spectra were obtained from the LC-UV/MS apparatus consisting of a Spectra System SN4000 interface, a Spectra System SCM1000 degasser, a Spectra System P1000XR pump, a Spectra System AS3000 autosampler, and a Finnigan LCQ Classic ion trap mass spectrometer in positive ion mode (all Thermo, San José, CA, USA), mass to charge range $\mathrm{m} / \mathrm{z}$ 100 to $\mathrm{m} / \mathrm{z} 2000$ at unit resolution and with a peak width of 0.25 daltons/z, equipped with a Waters 2487 dual wavelength UV detector (Waters, Milford, MA, USA) and Xcalibur 2.0 software (Thermo) for data acquisition. ESI was conducted using a needle voltage of $4.5 \mathrm{kV}$. Nitrogen was used as sheath and auxiliary gas with the heated capillary set at $250^{\circ} \mathrm{C}$. UV-detection was used for quantification (at $266 \mathrm{~nm}$ ), while ESI-ion trap MS detection was used for identification.

LC determination of impurities in lumefantrine samples was performed using a Purospher STAR RP-18 endcapped $(150 \times 4.6 \mathrm{~mm}, 5 \mu \mathrm{m}$ particle size $)$ column (Merck, Darmstadt, Germany) with guard column at $30^{\circ} \mathrm{C}$ under isocratic conditions with a mobile phase consisting of ammonium acetate $(\mathrm{pH} 4.9 ; 0.1 \mathrm{M})$ and acetonitrile $(10: 90, \mathrm{v} / \mathrm{v})$. The flow rate was set at 2.0 $\mathrm{mL} / \mathrm{min}$ (minimal run time: $30 \mathrm{~min}$.). The injection volume was $10 \mu \mathrm{l}$. Under these conditions, lumefantrine elutes at approximately $22 \mathrm{~min}$. System suitability tests (SSTs) were established as the plate number on lumefantrine $\left(\mathrm{N} \geq 8.2 \times 10^{3}\right)$ and the oxidative stress degradation product $\left(\mathrm{N} \geq 2.4 \times 10^{3}\right)$, the signal-tonoise ratio of $0.5 \%$ l.c. lumefantrine solution $(\mathrm{S} / \mathrm{N} \geq$ 30 ), the peak area ratio of the $0.5 \%$ l.c. versus $100 \%$ l.c. (between 0.4 and 0.6 ) and the relative position of the in-situ prepared $\mathrm{N}$-oxide by $\mathrm{H}_{2} \mathrm{O}_{2}$ treatment (RRT between 0.12 and 0.22 ).

The LC method was validated for the determination of lumefantrine and its related impurities. The selectivity of the developed chromatographic method was established by the separation of lumefantrine and its impurities. A correlation coefficient $\left(\mathrm{r}^{2}\right)$ of 0.9998 for lumefantrine $(0.0006$ to $0.01 \mathrm{mg} / \mathrm{ml})$ and 1.0 for impurity A and DBK ( 0.001 to $0.1 \mathrm{mg} / \mathrm{ml})$ demonstrated that the HPLC method is linear in the lower range. LOD/LOQ values for lumefantrine, DBK and impurity A were calculated $(\mathrm{S} / \mathrm{N}=3$ resp. 10$): 0.004 \mathrm{mg} / \mathrm{ml}$ and $0.026 \mathrm{mg} / \mathrm{ml}$ for lumefantrine $(0.004 \%$ respectively $0.026 \%$ l.c. $)$, $0.011 \mathrm{mg} / \mathrm{ml}$ and $0.040 \mathrm{mg} / \mathrm{ml}$ for DBK $(0.012 \%$ respectively $0.042 \%$ l.c.) and $0.110 \mathrm{mg} / \mathrm{ml}$ and $0.393 \mathrm{mg} / \mathrm{ml}$ for impurity A $(0.115 \%$ respectively $0.409 \%$ l.c.). The analytical stability of lumefantrine, impurity A and DBK was confirmed over a storage period of 24 hours at $5^{\circ} \mathrm{C}$, i.e. the sample compartment temperature. Accuracy and precision were evaluated by repeated analysis $(n=6)$, with $102.6 \%$ l.c. recovery and $2.1 \%$, respectively $2.86 \%$, for repeatability, respectively intermediate precision.

The relative retention time (RRT) is defined as the ratio of the retention time of the compound versus the retention time of lumefantrine. The relative response factor is defined as the ratio of the area of the compound versus the area of lumefantrine, both injected at the same concentration.

\section{Forced degradation}

Forced degradation of lumefantrine API and FPP was performed under heat, light, acidic, alkaline and oxidative stress conditions. In heat stress studies, the FPP powder (one gram) was incubated at 40,50 and $60^{\circ} \mathrm{C}$ for respectively four, three and two days. The placebo powder (one gram) was incubated for two days at $60^{\circ} \mathrm{C}$. In light stress studies, the FPP and placebo powder (one gram) were subjected to UV (three days incubation) and VIS (seven days incubation) light in a qualified Pharma $500 \mathrm{~L}$ stability cabinet (Weiss Technik) according to ICH. Finally, FPP and placebo were stressed by adding $10 \mathrm{ml}$ of $1 \mathrm{M} \mathrm{HCl}$ (acidic), $1 \mathrm{M} \mathrm{NaOH}$ (alkaline) or $1 \%$ $\mathrm{H}_{2} \mathrm{O}_{2}$ (oxidative) to one gram of the powder to be examined. Samples were incubated, up to eight days, at $5,25,40,50$ and $60^{\circ} \mathrm{C}$. After the incubation, samples were neutralized using $\mathrm{NaOH}$ (acidic), $\mathrm{HCl}$ (alkaline) or $\mathrm{Na}_{2} \mathrm{~S}_{2} \mathrm{O}_{5}$ (oxidative), and the solvent evaporated using freeze-drying. The resulting powdered samples were dispersed in THF, centrifuged, HPLC-filtrated and analyzed using HPLC-DAD/UV-ESI/MS.

Additionally, different batches of FPP were included in long-term (up to 24 months, $30^{\circ} \mathrm{C}, 70-75 \% \mathrm{RH}$ ) and accelerated (up to 6 months, $40^{\circ} \mathrm{C}, 75 \% \mathrm{RH}$ ) stability studies according to ICH stability guidelines [24].

\section{In-silico toxicological predictions}

To make in-silico toxicological predictions for lumefantrine and its identified related impurities, two sources of toxicological predictions were used: Derek ${ }^{\circledR}$ (Nexus v2.0) for Windows developed by Lhasa Limited (Leeds, 
UK) and Toxtree ${ }^{\circledR}$ (v1.60) developed by Ideaconsult Ltd. (Sofia, Bulgaria). Derek ${ }^{\mathbb{B}}$ (Nexus v2.0) for Windows is an expert knowledge base system, containing descriptions of molecular substructures which have been associated with toxic endpoints (structural alerts), that predicts whether a chemical is toxic in humans, other mammals and bacteria. The programme applies structure-activity relationships ((Q)SARs) and other expert knowledge rules to derive a reasoned conclusion about the potential toxicity of the query chemical $[25,26]$. Toxtree $^{\circledR}$ is an open source application, which is able to estimate toxic hazards by applying a decision tree approach and making structure-based predictions for a number of toxicological endpoints using different modules. Hazard estimations were generated using three Toxtree $^{\circledR}$ modules: Cramer rules with extensions, Benigni/Bossa rulebase and structure alerts for the in vivo micronucleus assay in rodents.

\section{Results and discussion}

\section{HPLC analysis of lumefantrine containing samples}

As the Ph.Int./USP Salmous HPLC methods $[17,18]$ are a complex, step-wise gradient using an ion-pairing reagent, this method is not compatible with MS detection. Moreover, the gradient is required for the detection of synthesis impurities $B_{A}$ and $B_{B}$, which are structurally very different from lumefantrine and its other impurities, especially degradants. Therefore, an isocratic RP-HPLC method was used without an MSincompatible ion-pairing reagent. The chromatographic characteristics of these two synthesis impurities on this system could not be evaluated, due to the unavailability of references for these impurities.

Lumefantrine API and FPPs were exposed to diverse stress conditions for different periods. Additionally, FPPs were put on long-term and accelerated stability studies as well according to ICH. FPP samples in the long-term stability study were kept for up to twenty-four months at $30^{\circ} \mathrm{C} / 75 \% \mathrm{RH}$. In the accelerated study, the stability conditions were adjusted and FPP samples were kept for up to six months at $40^{\circ} \mathrm{C} / 75 \% \mathrm{RH}$. The unstressed and stressed API samples, as well as the unstressed (release), accelerated, long-term and stressed FPP samples were analyzed with the validated HPLC method. Five synthesis and four stress related lumefantrine impurities have been observed in lumefantrine containing samples (Table 1). The relative retention time (RRT), relative to lumefantrine, of these impurities was defined and normalized quantification was performed with a reporting threshold of $0.10 \%$. Maximal actually observed levels of lumefantrine related impurities in different samples under different conditions were obtained (Table 2). None of these lumefantrine related impurities were observed above the reporting threshold (i.e. $>0.10 \%$ ) in unstressed API and release $\left(T_{0}\right)$ FPP samples, except for the monodesbutyl derivative. However, these lumefantrine degradants were observed in stressed API and FPP samples, and in FPP stability studies. Compounds 1,2 and 3 were observed in oxidative stressed API samples. Three lumefantrine related impurities were observed in stressed FPP stability

\section{Table 1 Structural information for the observed and/or reported lumefantrine related impurities}

\begin{tabular}{|c|c|c|c|}
\hline \# & Compound [formula, mono-isotopic mass] & Structure & Origin \\
\hline 1 & Desbenzylketo $\mathrm{N}$-oxide $\left[\mathrm{C}_{23} \mathrm{H}_{27} \mathrm{NO}_{3} \mathrm{Cl}_{2}, \mathrm{MW} 435.14\right]$ & & $\begin{array}{l}\text { Alkaline stress } \\
\text { Oxidative stress }\end{array}$ \\
\hline 2 & Lumefantrine (mono-)desbutyl derivative $\left[\mathrm{C}_{26} \mathrm{H}_{24} \mathrm{NOCl}_{3}, \mathrm{MW} 473.09\right]$ & & $\begin{array}{l}\text { Oxidative stress } \\
\text { Metabolite }\end{array}$ \\
\hline 3 & Lumefantrine $\mathrm{N}$-oxide $\left[\mathrm{C}_{30} \mathrm{H}_{32} \mathrm{NO}_{2} \mathrm{Cl}_{3}, \mathrm{MW}\right.$ 543.15] & & $\begin{array}{l}\text { Oxidative stress } \\
\text { Degradation }\end{array}$ \\
\hline 4 & $\begin{array}{l}\text { 2,7-dichloro-4-[2-(di-n-butylamino)-1-hydroxyethyl]-9H-fluoren-9-one; Desbenzylketo derivative }(\mathrm{DBK})\left[\mathrm{C}_{23} \mathrm{H}_{27} \mathrm{NO}_{2} \mathrm{Cl}_{2}\right. \\
\text { MW 419.14] }\end{array}$ & & $\begin{array}{c}\text { Oxidative stress } \\
\text { Acidic stress } \\
\text { Degradation }\end{array}$ \\
\hline 5 & 2-(di-n-butylamino)-1-[2,7-dichloro-9H-fluoren-4-yl]ethanol; Desbenzyl derivative $\left[\mathrm{C}_{23} \mathrm{H}_{29} \mathrm{NOCl}_{2}, 405.16\right]$ & & Synthesis \\
\hline 6 & Synthesis impurity found in lumefantrine API; Lumefantrine oxide $\left[\mathrm{C}_{30} \mathrm{H}_{32} \mathrm{NO}_{2} \mathrm{Cl}_{3}, \mathrm{MW}\right.$ 543.14] & & Synthesis \\
\hline 7 & Synthesis impurity found in lumefantrine API; Lumefantrine oxide $\left[\mathrm{C}_{30} \mathrm{H}_{32} \mathrm{NO}_{2} \mathrm{Cl}_{3}, \mathrm{MW}\right.$ 543.14] & & Synthesis \\
\hline 8 & $\begin{array}{l}\text { (RS,Z)-2-(Dibutylamino)-2-(2,7-dichloro-9-(4-chloro-benzylidene)-9H-fluoren-4-yl)ethanol (isomeric compound); } \\
\text { Impurity A (Ph. Int./USP Salmous) }\left[\mathrm{C}_{30} \mathrm{H}_{32} \mathrm{NOCl}_{3}, \mathrm{MW} 527.15\right]\end{array}$ & & Synthesis \\
\hline 9 & Synthesis impurity found in lumefantrine API; Lumefantrine oxide $\left[\mathrm{C}_{30} \mathrm{H}_{32} \mathrm{NO}_{2} \mathrm{Cl}_{3}, \mathrm{MW} 543.14\right]$ & & Synthesis \\
\hline 10 & $\begin{array}{l}\text { (1S,3R,5R)-1,3-bis((EZ)-2,7-Dichloro-9-(4-chlorobenzyl-idene)-9H-fluoren-4-yl)-2,6-dioxabicyclo[3.1.0]hexane; Impurity B } \\
\text { (USP Salmous) }\left[\mathrm{C}_{44} \mathrm{H}_{24} \mathrm{Cl}_{6} \mathrm{O}_{2}, 797.39\right]\end{array}$ & & Synthesis \\
\hline 11 & $\begin{array}{l}\text { 2-((EZ)-2,6-Dichloro-9- (4-chlorobenzylidene)-9H-fluoren-4-yl)-3'-((EZ)-2,7-dichloro-9-(4-chlorobenzylidene)-9H-fluoren- } \\
\text { 4-yl)-2,2'-bioxirane; Impurity BB (USP Salmous) }\left[\mathrm{C}_{44} \mathrm{H}_{24} \mathrm{Cl}_{6} \mathrm{O}_{2}, 797.39\right]\end{array}$ & ais? & Synthesis \\
\hline
\end{tabular}


Table 2 Percentage maximum actual levels of lumefantrine related impurities observed ${ }^{(1)}$

\begin{tabular}{|c|c|c|c|c|c|c|}
\hline \multirow[t]{2}{*}{ \# } & \multirow[t]{2}{*}{ Compound } & \multicolumn{2}{|c|}{ API } & \multicolumn{3}{|c|}{ FPP } \\
\hline & & Unstressed & Stressed & Release & Accelerated & Stressed \\
\hline 1 & Desbenzylketo N-oxide & & 1.39 & & & 0.60 \\
\hline 2 & Monodesbutyl derivative & & 0.56 & 0.11 & & \\
\hline 3 & Lumefantrine $\mathrm{N}$-oxide & & 21.32 & & 0.12 & 0.86 \\
\hline 4 & Desbenzylketo derivative & & & & 0.34 & 4.26 \\
\hline 5 & Desbenzyl derivative & & & & & \\
\hline 6 & Lumefantrine oxide (RRT 0.49) & & & & & \\
\hline 7 & Lumefantrine oxide (RRT 0.52) & & & & & \\
\hline 8 & Impurity A & & & & & \\
\hline 9 & Lumefantrine oxide (RRT 0.59) & & & & & \\
\hline
\end{tabular}

samples: compound $1\left(60^{\circ} \mathrm{C}, 1 \mathrm{M} \mathrm{NaOH}, \mathrm{T}_{2 \mathrm{~d}}\right)$, compound $3\left(60^{\circ} \mathrm{C}, 1 \% \mathrm{H}_{2} \mathrm{O}_{2}, \mathrm{~T}_{2 \mathrm{~d}}\right)$ and compound $4\left(50^{\circ} \mathrm{C}, 1\right.$ $\left.\mathrm{M} \mathrm{HCl}, \mathrm{T}_{3 \mathrm{~d}}\right)$. Compound 3 and 4 were also detected in the accelerated $\left(40^{\circ} \mathrm{C} / 75 \% \mathrm{RH}, \mathrm{T}_{6 \mathrm{~m}}\right)$ and long-term stability studies. A typical UV chromatogram illustrating the separation of lumefantrine $\mathrm{N}$-oxide, DBK, desbenzyl lumefantrine derivative and lumefantrine is given in Figure 2.

\section{Identification of lumefantrine impurities with LC-MS/MS}

The observed lumefantrine impurity peaks (related to synthesis as well as degradation processes) in stressed

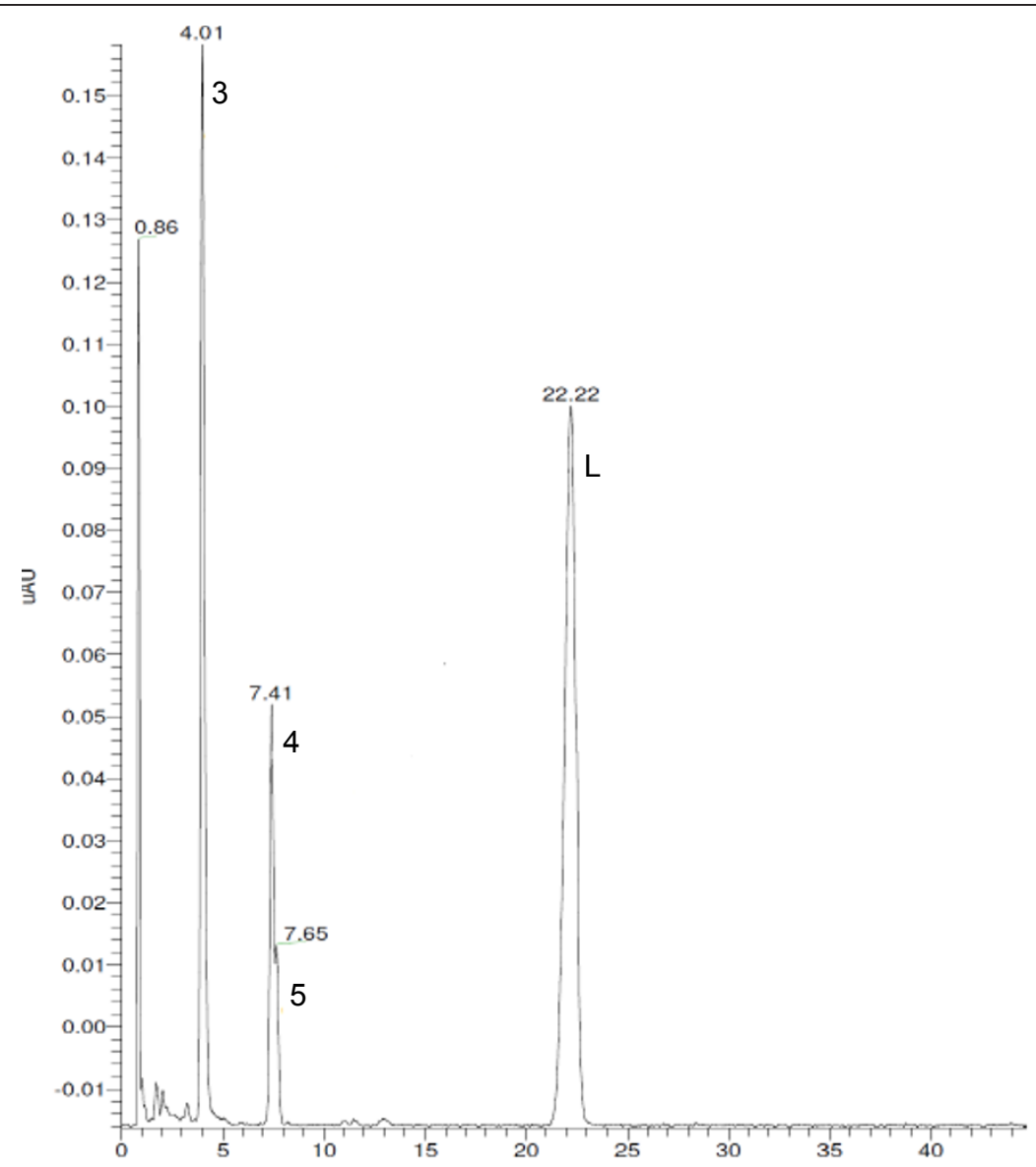

Figure 2 UV chromatogram of a mixed sample illustrating lumefantrine $\mathrm{N}$-oxide, lumefantrine DBK and desbenzyl derivative and lumefantrine. UV chromatogram of a mixed sample illustrating lumefantrine N-oxide (3), DBK (4) and desbenzyl lumefantrine derivative (5) and lumefantrine $(\mathrm{L})$. 
or unstressed API and FPPs were identified using LCMS/MS, with one of them investigated for the first time and proposed as a new specified lumefantrine related impurity. The desbutyl, desbenzyl and isomeric compound A derivatives are already known lumefantrine impurities. The analytical characteristics of the remaining unidentified lumefantrine related impurities were obtained by analysis of MS data: $m / z$ values (Table 3), isotopic-distributions in mass spectra (Figure 2) and MS/MS (fragmentation pattern for structural identification).

The mono-isotopic mass of lumefantrine [(1RS)-2(Dibutylamino)-1-[(Z)-2,7-dichloro-9-(4-chlorobenzylidene)-9H-fluoren-4-yl] ethanol] was calculated to be 527.15. The mass spectrum of lumefantrine main peak indicated the most abundant ion at an $\mathrm{m} / z$-ratio of 528.10 , with an isotopic distribution corresponding to the three chlorine atoms in its structure $\left({ }^{35} \mathrm{Cl}\right.$ at $75.77 \%$ and ${ }^{37} \mathrm{Cl}$ at $\left.24.23 \%\right)$. In the mass spectrum of compound 1 (RRT $\sim 0.08$ ), 436.14 is observed to be the most abundant $m / z$. The isotopic distribution is suggestive for a compound possessing two chlorine atoms, and is identical to the isotopic distribution of compound 4 . The most abundant $m / z$ value for compound 4 is 420.13 , with a molecular formula of $\mathrm{C}_{23} \mathrm{H}_{27} \mathrm{NO}_{2} \mathrm{Cl}_{2}$, i.e. desbenzylketo derivative (DBK). This MS-derived structure was confirmed by chemical synthesis of a DBK reference and its IR and NMR spectroscopic structure confirmation. This DBK reference standard gave similar chromatographic retention characteristics as well as DAD-UV spectrum as degradant 4 found in the samples. Based on the observed $m / z$ values of compound 1 and DBK, compound 1 has an additional oxide to its structure, and is thus assigned as being the N-oxide of DBK. The most abundant ion found for compound 2 was $m / z 474.00$. Its isotopic distribution is characteristic for a compound possessing three chlorines and the molecular formula

Table 3 HPLC characteristics of lumefantrine related impurities

\begin{tabular}{llccc}
\hline$\#$ & Compound & $\mathbf{R T}^{(\mathbf{1})}$ & $\mathbf{R R T}^{(\mathbf{2})}$ & $\begin{array}{c}\text { Most abundant } \\
\mathbf{m} / \mathbf{z} \text { observed }\end{array}$ \\
\hline 1 & Desbenzylketo N-oxide & 1.79 & 0.08 & 436.14 \\
2 & Monodesbutyl derivative & 3.25 & 0.15 & 474.00 \\
3 & Lumefantrine N-oxide & 3.96 & 0.17 & 544.08 \\
4 & Desbenzylketo derivative & 7.41 & 0.33 & 420.13 \\
5 & Desbenzyl derivative & 7.69 & 0.34 & 406.09 \\
6 & Lumefantrine oxide & 10.96 & 0.49 & 544.12 \\
7 & Lumefantrine oxide & 11.45 & 0.52 & 544.12 \\
8 & Impurity A & 12.70 & 0.58 & 528.10 \\
9 & Lumefantrine oxide & 12.97 & 0.59 & 544.12 \\
L & Lumefantrine & 22.28 & 1.00 & 528.10 \\
\hline
\end{tabular}

(1) Retention time (min.).

(2) Relative retention time.
$\mathrm{C}_{26} \mathrm{H}_{24} \mathrm{NOCl}_{3}$, i.e. the monodesbutyl derivative. As this compound is more hydrophilic than lumefantrine, it elutes much earlier than lumefantrine. Compound 3 was found in the oxidative stressed FPP samples. Its most abundant $\mathrm{m} / \mathrm{z}$ is 544.08 , with an isotopic distribution corresponding to that of lumefantrine, giving the molecular formula $\mathrm{C}_{30} \mathrm{H}_{24} \mathrm{NO}_{2} \mathrm{Cl}_{3}$. Based on the observed $\mathrm{m}$ / $z$ values of compound 3 and lumefantrine, compound 3 has an additional oxide to its structure. MS/MS fragmentation spectra, by collision induced dissociation (CID, energy $100 \mathrm{eV}$ ), of compound 3 showed peaks at $m / z 526.12$ (loss of $\mathrm{H}_{2} \mathrm{O}$ ), 470.10, 396.99, 380.95, 346.23, 305.58, 298.06 (loss of $\mathrm{C}_{14} \mathrm{H}_{7} \mathrm{Cl}_{2}$ ) and 152.30. This impurity was thus identified as lumefantrine $\mathrm{N}$-oxide. Compounds 6,7 and 9 gave identical mass spectra (Figure 3) with the most abundant ion found at $m / z 544.12$. The isotopic distributions are characteristic for a compound containing three chlorines and a molecular formula $\mathrm{C}_{30} \mathrm{H}_{32} \mathrm{NO}_{2} \mathrm{Cl}_{3}$, i.e. oxides of lumefantrine. As these three impurities are eluting at different retention time, they are most probably isomeric compounds with an $-\mathrm{OH}$ function at different positions on the lumefantrine aromatic ring structure.

\section{Specified lumefantrine impurity DBK}

The lumefantrine-related compound 4, DBK (RRT 0.33 ), was not only formed in stress stability samples, but was also observed in accelerated and stressed stability samples of FPP. Moreover, DBK was found to be present in market samples at a concentration ranging between $0.03 \%$ and $0.12 \%$, determined by area normalization. Subsequently, DBK was synthesized for further analytical characterization, including confirmation of its relative retention time (RRT) and determination of its relative response factor (RFF) at the detection wavelength of $266 \mathrm{~nm}$. The RRT and the RRF of DBK relative to lumefantrine were experimentally determined to be 0.33 and 2.87 respectively. The DAD-UV spectra recorded for lumefantrine and DBK (Figure 4) showed the wavelength of maximum absorption to be higher for DBK (app. $266 \mathrm{~nm}$ ) than for lumefantrine (app. $234 \mathrm{~nm}$ ), due to the benzyl group being replaced by the keto function. This impurity was observed in oxidative and acidic stress degradation, as well as in the accelerated and long-term ICH stability studies, justifying this degradant to be classified as a specified degradant.

\section{In-silico toxicological predictions of lumefantrine and its related impurities}

Using the knowledge-based expert systems Toxtree ${ }^{\circledR}$ and Derek $^{\circledR}$, general toxicological and carcinogenic alerts for lumefantrine, as well as for its related observed and already described impurities, have been investigated. Since DBK is a specified lumefantrine-related compound, 


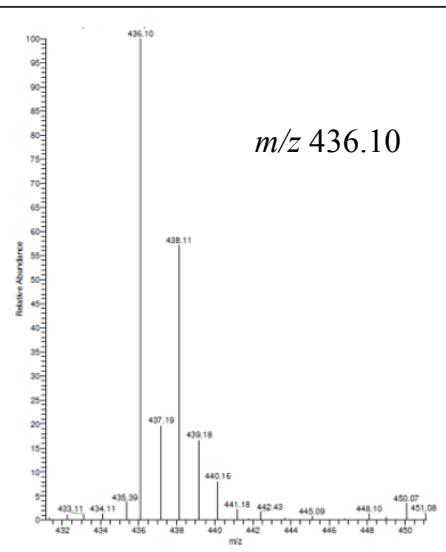

(1)

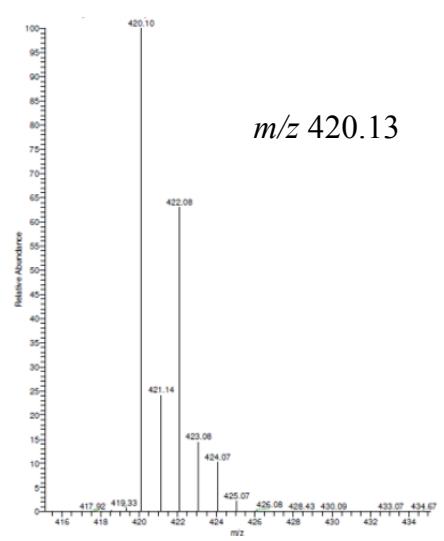

(4)

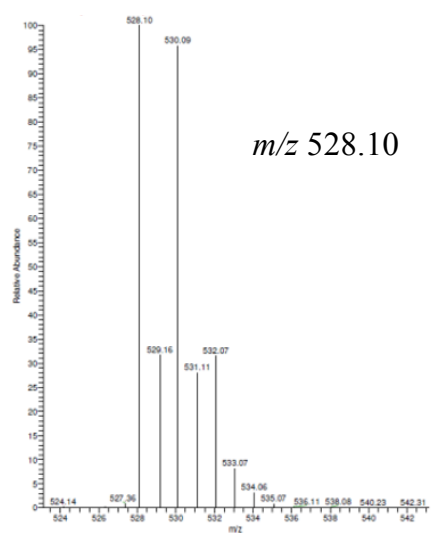

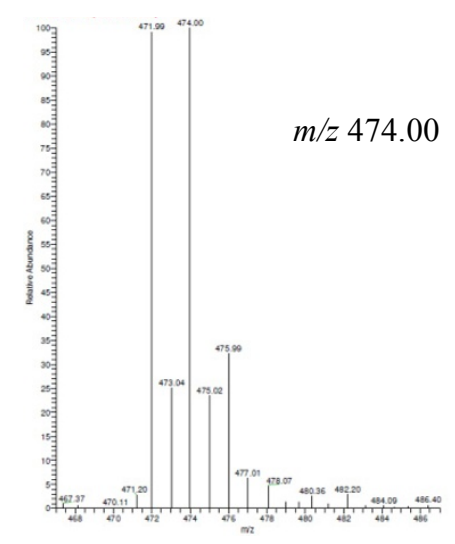

(2)

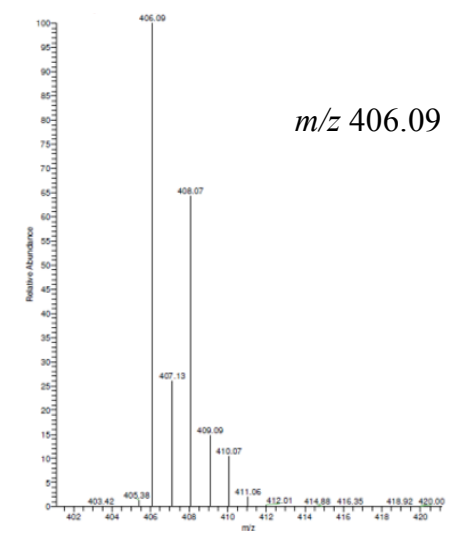

(5)

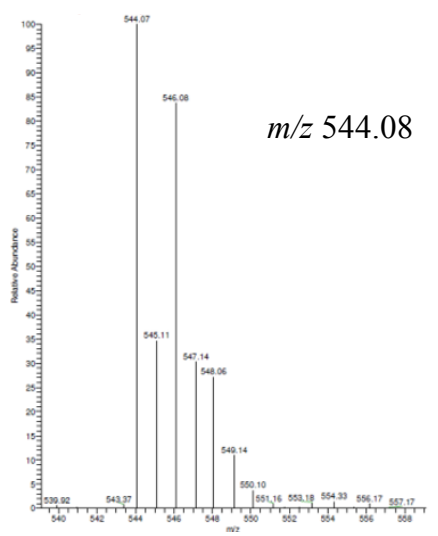

(3)

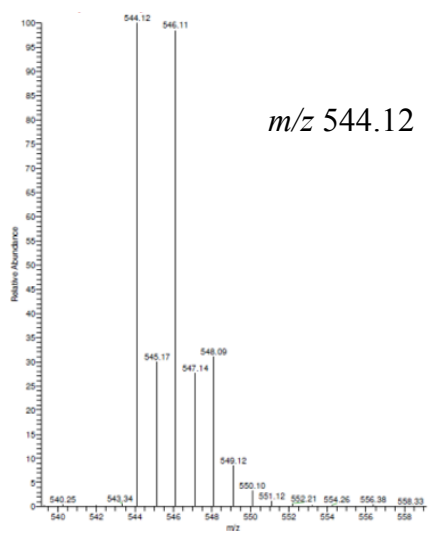

$(6,7,9)$

(8)

Figure 3 Isotopic-distribution mass spectra of lumefantrine related impurities with the most abundant $\mathrm{m} / \mathrm{z}$ observed. Isotopicdistribution mass spectra of lumefantrine related impurities: (1) Desbenzylketo N-oxide; (2) Monodesbutyl derivative; (3) Lumefantrine N-oxide; (4) Desbenzylketo derivative; (5) Desbenzyl derivative; $(6,7,9)$ Oxide of lumefantrine and (8) Impurity A (USP/Ph.Int). 

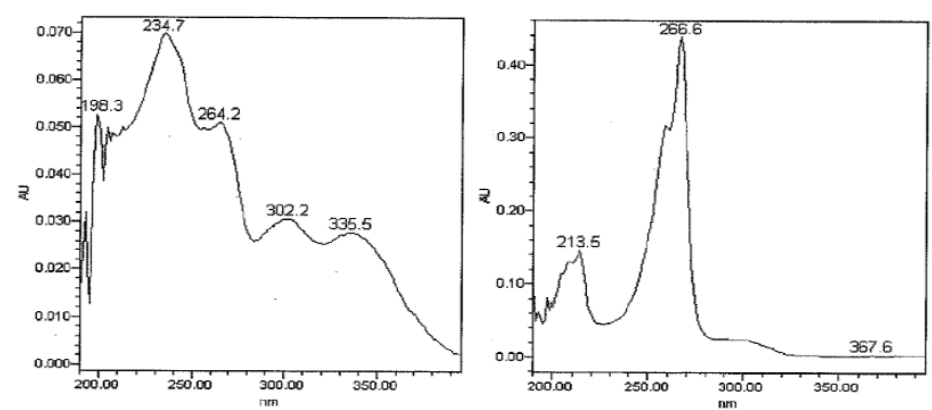

Figure 4 UV spectra recorded for lumefantrine (left) and DBK (right) showing the observed wavelength of maximum absorption. DADUV spectra of lumefantrine (left) and DBK (right).

the toxicity profile of DBK is of paramount importance. Based on the Cramer rules with extensions, Toxtree ${ }^{\circledR}$ clearly predicted general toxicity risks (class III), and genotoxic alerts (polycyclic aromatic hydrocarbons, halogenated benzene and $\mathrm{H}$-acceptor-path3- $\mathrm{H}$-acceptor) for DBK, which are identical to the API lumefantrine itself. According to the toxicological concern (TTC), the daily dosage for compounds classified in class III should be below $90 \mu \mathrm{g} /$ person $(60 \mathrm{~kg}) /$ day to be validated as non toxic [27]. Hence, the TTC value of $90 \mu \mathrm{g}$ on the MDD of $960 \mathrm{mg}$ lumefantrine corresponds to a limit of $0.01 \%$ (90 $\mu \mathrm{g} / 960 \mathrm{mg}$ ), which is far below the levels actually observed.

The toxicity profile by Derek ${ }^{\circledR}$ of DBK is defined by several general toxicity alerts which are similar to lumefantrine: hERG channel inhibion and $\alpha_{2} \mu^{\text {-globulin }}$ nephropathy [28] plus additional photo-toxicity and -allergenicity. However, Derek ${ }^{\circledR}$ did not trigger any genotoxicity or carcinogenicity for DBK.

The other lumefantrine related impurities were also predicted in Toxtree ${ }^{\circledR}$ to have a high general toxicity similar to lumefantrine itself (depicted Class III), based on the Cramer rules with extensions, and genotoxicity risks. Again, Derek ${ }^{\circledR}$ clearly indicated a limit toxicity profile for the majority of lumefantrine related impurities compared to lumefantrine (hERG channel inhibion, $\alpha_{2 \mu}$-globulin nephropathy). Only impurity $B_{B}$ triggered additional toxicity alerts (carcinogenicity/mutagenicity, chromosome damage, eye/skin irritation, developmental toxicity, skin sensitization), indicative for a non-toxic profile compared to lumefantrine itself.

\section{Conclusions}

An exhaustive impurity profiling of lumefantrine was performed using HPLC-UV/ESI-ion trap MS. From unstressed, stressed and accelerated stability samples of lumefantrine API and FPPs, nine compounds were detected and characterized to be lumefantrine related impurities. One new lumefantrine related compound, DBK, was identified and characterized as a specified degradation impurity of lumefantrine in real market samples (FPPs). The in-silico toxicological investigation (Toxtree $^{\circledR}$ and Derek ${ }^{\circledR}$ ) indicated overall a lesser toxicity for the specified impurity DBK compared to the API lumefantrine itself.

\section{Acknowledgements}

The authors would like to thank Dafra Pharmaceuticals (Turnhout, Belgium) for the provision of the reference substances, as well as their interest and support in this investigation. Moreover, one of the authors (SS) is supported by the Epidemiology and Modeling Project within the Institutional University Cooperation Programme (Jimma University) of VLIR.

\section{Author details}

${ }^{1}$ Drug Quality and Registration (DruQuaR) group, Faculty of Pharmaceutical Sciences, Ghent University, Harelbekestraat 72, B-9000 Ghent, Belgium.

${ }^{2}$ Department of Physiology and Biometrics, Faculty of Veterinary Medicine, Ghent University, Salisburylaan 133, B-9820 Merelbeke, Belgium. ${ }^{3}$ School of Pharmacy, Jimma University, Jimma, Ethiopia. ${ }^{4}$ Foundation ACT-ion Afrique, B-1000 Brussel, Belgium.

\section{Authors' contributions}

MV and SS did part of the analytical experiments incl. validation, performed the in-silico verification and wrote the article. BB, EVG and SVD did part of the analytical experiments, incl. stability and MS experiments and QC on data. CB and LD critically reviewed and discussed this manuscript. FHJ designed the experiments, overviewed the DBK reference synthesis, and critically reviewed the manuscript. BDS was the overall study director, responsible for design of experiments, interpretation of data and writing this manuscript. All authors read and approved the final manuscript.

\section{Competing interests}

The authors, MV, BB, EVG and BDS would like to acknowledge that Dafra sponsored the analytical development. However, these authors do not work for, or represent in any way, Dafra. FHJ is partly working for Dafra.

Received: 23 December 2010 Accepted: 28 February 2011 Published: 28 February 2011

\section{References}

1. Falade C, Makanga M, Premji Z, Ortmann CE, Stockmeyer M, de Palacios PI: Efficacy and safety of artemether-lumefantrine (Coartem (R)) tablets (sixdose regimen) in African infants and children with acute) uncomplicated falciparum malaria. Trans R Soc Trop Med Hyg 2005, 99:459-467.

2. Hatz C, Abdulla S, Mull R, Schellenberg D, Gathmann I, Kibatala P, Beck HP, Tanner M, Royce C: Efficacy and safety of CGP 56697 (artemether and benflumetol) compared with chloroquine to treat acute falciparum malaria in Tanzanian children aged 1-5 years. Trop Med Int Health 1998, 3:498-504. 
3. van Vugt M: Concerns about the privatization of public goods: A social dilemma analysis. Soc Psychol Q 1997, 60(4):355-367.

4. van Vugt M, Looareesuwan S, Wilairatana P, McGready R, Villegas L, Gathmann I, Mull R, Brockman A, White NJ, Nosten F: Artemetherlumefantrine for the treatment of multidrug-resistant falciparum malaria. Trans R Soc Trop Med Hyg 2000, 94:545-548.

5. vonSeidlein L, Jaffar S, Pinder M, Haywood M, Snounou G, Gemperli B Gathmann I, Royce C, Greenwood B: Treatment of African children with uncomplicated falciparum malaria with a new antimalarial drug, CGP 56697. J Infect Dis 1997, 176:1113-1116.

6. de Villiers KA, Egan TJ: Recent advances in the discovery of haemtargeting drugs for malaria and schistosomiasis. Molecules 2009, 14:2868-2887.

7. Traebert M, Dumotier B, Meister L, Hoffmann P, Dominguez-Estevez M, Suter W: Inhibition of hERG K+ currents by antimalarial drugs in stably transfected HEK293 cells. Eur J Pharmacol 2004, 484:41-48.

8. Pirker-Krassnig DK, Wernsdorfer $G$, Sirichaisinthop J, Rojanawatsirivet $C$, Kollaritsch $\mathrm{H}$, Wernsdorfer WH: Comparative study on the in vitro activity of lumefantrine and desbutyl-benflumetol in fresh isolates of Plasmodium vivax from Thailand. Wien Klin Wochenschr 2004, 116:47-52.

9. Wernsdorfer WH, Landgraf B, Kilimali V, Wernsdorfer G: Activity of benflumetol and its enantiomers in fresh isolates of Plasmodium falciparum from East Africa. Acta Trop 1998, 70:9-15.

10. Ballereau F, Prazuck T, Schrive I, Lafleuriel MT, Rozec D, Fisch A, Lafaix C: Stability of essential drugs in the field: Results of a study conducted over a two-year period in Burkina Faso. Am J Trop Med Hyg 1997, 57:31-36.

11. Bari SBKB, Jaiswal YS, Shikhedkar AA: Impurity profile: Significance in active pharmaceutical ingredient. Eurasian J Anal Chem 2007, 2(1):32-53.

12. Vergote V, Burvenich C, Van de Wiele C, De Spiegeleer B: Quality specifications for peptide drugs: a regulatory-pharmaceutical approach. $J$ Pept Sci 2009, 15:697-710.

13. De Spiegeleer B, Vergote V, Pezeshki A, Peremans K, Burvenich C: Impurity profiling quality control testing of synthetic peptides using liquid chromatography-photodiode array-fluorescence and liquid chromatography-electrospray ionization-mass spectrometry: The obestatin case. Anal Biochem 2008, 376:229-234.

14. Nicolas EC, Scholz TH: Active drug substance impurity profiling - Part I. LC/UV diode array spectral matching. J Pharm Biomed Anal 1998, 16:813-824.

15. Roy J: Pharmaceutical impurities - A mini review. AAPS PharmSciTech 2002, 3:article 6.

16. ICH guidelines - International Conference on Harmonization, Q3A(R2) Impurities in new drug substances CPMP/ICH/2737/99. (October 2006). [http://www.ema.europa.eu/docs/en_GB/document_library/ Scientific_guideline/2009/09/WC500002675.pdf], [Accessed on 5 November 2010 at 11:06]

17. Authorized Lumefantrine USP Salmous Standard (Februari 2009). [http:// www.usp.org/pdf/EN/nonUSStandards/lumefantrine.pdf], [Accessed on 24 October 2010 at 17:14].

18. Lumefantrine: Document QAS/06.186/FINAL (WHO Ph. Int. - July 2008). [http://www.who.int/medicines/publications/pharmacopoeia/ Lumef_monoFINALQAS06_186_July08.pdf], [Accessed on 24 October 2010 at 17:37].

19. Lee H: Pharmaceutical applications of liquid chromatography coupled with mass spectrometry (LC/MS). J Liq Chromatogr Relat Technol 2005, 28:1161-1202.

20. Cesar ID, Nogueira FHA, Pianetti GA: Simultaneous determination of artemether and lumefantrine in fixed dose combination tablets by HPLC with UV detection. J Pharm Biomed Anal 2008, 48:951-954.

21. Cesar ID, Nogueira FHA, Pianetti GA: Comparison of HPLC, UV spectrophotometry and potentiometric titration methods for the determination of lumefantrine in pharmaceutical products. J Pharm Biomed Anal 2008, 48:223-226.

22. Patil KR, Rane VP, Sangshetti JN, Shinde DB: A Stability-Indicating LC Method for Lumefantrine. Chromatographia 2009, 69:375-379.

23. Munjal V, Paliwal N, Chaursia BK, Varshney B, Ahmed T, Paliwal J: LCtandem mass spectrometry method for quantification of lumefantrine in human plasma and its application to bioequivalence study. Chromatographia 2010, 71:505-510.
24. ICH guidelines - International Conference on Harmonization, Q1A(R2) Stability testing of new drug substances and products CPMP//CH/2736/ 99. (August 2003). [http://www.ema.europa.eu/docs/en_GB/ document_library/Scientific_guideline/2009/09/WC500002651.pdf], [Accessed on 5 November 2010 at 12:10].

25. Ellison CM, Madden JC, Judson P, Cronin MTD: Using in silico tools in a weight of evidence approach to aid toxicological assessment. Mol Inf 2010, 29:97-110.

26. Mohan CG, Gandhi T, Garg D, Shinde R: Computer-assisted methods in chemical toxicity prediction. Mini Rev Med Chem 2007, 7:499-507.

27. Munro IC, Renwick AG, Danielewska-Nikiel B: The threshold of toxicological concern (TTC) in risk assessment. Toxicol Lett 2008, 180:151-156.

28. Kristiansen E, Madsen C: Induction of protein droplet (alpha(2-mu)globulin) nephropathy in male-rats after short-term dosage with 1,8cineole and L-limonene. Toxicol Lett 1995, 80:147-152.

doi:10.1186/1475-2875-10-51

Cite this article as: Verbeken et al: Stability-indicating HPLC-DAD/UVESI/MS impurity profiling of the anti-malarial drug lumefantrine. Malaria Journal 2011 10:51.

\section{Submit your next manuscript to BioMed Central and take full advantage of:}

- Convenient online submission

- Thorough peer review

- No space constraints or color figure charges

- Immediate publication on acceptance

- Inclusion in PubMed, CAS, Scopus and Google Scholar

- Research which is freely available for redistribution 